\title{
ABPol 10 anos - Contribuições e Perspectivas
}

Completar 10 anos significa para a ABPol muito mais que a vitória sobre a adversidade, mas o triunfo pela criação de uma consciência em polímeros no Brasil. O entusiasmo demonstrado nos primeiros anos de criação sequer chegou a arrefecer pois a Associação, nesse momento já estruturada, passou a mostrar todo o seu potencial, reunindo a comunidade em eventos, oferecendo serviços, atendendo aos anseios de um sem número de profissionais que almejavam uma identidade própria para o setor de polímeros. A presente matéria conta um pouco dessa luta, e por que o aniversário comemorado em 23 de setembro tem um doce sabor.

\section{Histórico}

Pioneiro na história da ABPol, e um de seus mais ardorosos defensores, o Prof. Sílvio Manrich relatou a "Polímeros: Ciência e Tecnologia" como nasceu a idéia da instituição: "Entre os primeiros envelopes fechados por meus filhos e minha esposa na sala de jantar onde instalamos o $1^{\circ}$ escritório da ABPol até a edição deste número da revista, transcorreram 10 anos de dedicação, compreendidos por muitos sócios como a missão da ABPol e, por poucos, como obrigação. A partir de uma longa prosa entre professores da área de polímeros do DEMa/UFSCar (Rosario Bretas, Elias Hage, Sebastião Canevarolo, José Alexandrino de Sousa, José Augusto Agnelli, Luiz Antonio Pessan, Sílvio Manrich, entre outros), que viam a necessidade da existência de um veículo de comunicação para divulgação de artigos técnico-científicos é que surgiu a determinação de se criar a ABPol. Em fevereiro de 1988 foi feita uma con- sulta à comunidade (empresas, universidades e centros de $P \& D$ ) sobre a viabilidade e o momento oportuno de se nuclear uma associação de porte nacional. Dentre variadas opiniões prevaleceu a euforia e a determinação de se concretizar tal ideal. Em 23 de setembro de 1988, após a cerimônia de fundação, um repórter me perguntou se a data foi propositadamente escolhida para uma investida daquela envergadura, pois a primavera que começava naquele dia simboliza muito mais que o desabrochar das flores: simboliza um período repleto de vida e dinamismo."

A solenidade de fundação da Associação Brasileira de Polímeros (na época conhecida por $\mathrm{ABP}$ ) se deu no Anfiteatro Ala Norte da Universidade Federal de São Carlos, em 23 de setembro de 1988, com a presença de 126 participantes representando as diversas categorias profissionais ligadas ao setor: estudantes, professores universitários e profissionais da indústria. Patrocinaram o evento o
Depto. de Engenharia de Materiais e o Programa de Pós-Graduação em Ciência e Engenharia de Materiais da UFSCar, Polisul Petroquímica, Resana Participações S/A, Polialden Petroquímica, Polipropileno S/A e IBM Brasil Ltda.

Conforme lembrado pelo Prof. Sílvio Manrich, entre as pessoas que compuseram a mesa durante a cerimônia estava a Prof $^{a}$ Eloisa B. Mano, do IMA, que lembrou ao discursar que "é muito fácil criar uma entidade como a ABPol; o difícil é, sem sombra de dúvidas, fazê-la crescer, funcionar e atingir os seus objetivos", fato comprovado ao longo dos 10 anos da Associação. O Sr. Jan Orberg (Resana), em uma das primeiras reuniões da Diretoria Provisória, da qual era vice-presidente, continuando nesse cargo com a eleição da $1^{\text {a }}$ diretoria eleita, mencionou ao ver os primeiros resultados da entidade: "o que nasce certo é visto por nós com naturalidade". Na ocasião, a Sra. Zoé Moncorvo (Pepasa), vice- 
presidente na $2^{\text {a }}$ Diretoria eleita, lembrou aos presentes a necessidade de a ABPol manter sua postura: "A ABPol nunca pode deixar de ter aquilo que acho ser sua maior virtude: a imparcialidade". É essa imparcialidade que fez com que os sócios, ao longo dos anos, primassem pela qualidade de seus serviços e atividades, independentemente do público alvo de cada ação. Foi o caso dos congressos que atingiram um padrão internacional pela qualidade e abrangência. Outra prova dessa imparcialidade aliada à qualidade é a revista da
ABPol, que resultou na indexação pelo Chemical Abstracts e Rapra

Em 1988, tal como hoje, os objetivos da Associação estavam claramente definidos: promover os polímeros nos planos científico, tecnológico, artístico, didático e de cultura geral, assim como promo-

\section{ABPol 10 anos - Realizações}

\section{Treinamento:}

- 99 cursos abertos com instrutores do Brasil e

- 10 com instrutores do exterior

- 1.724 horas/aula -2.159 participantes

- 36 cursos in company

- 735 horas/aula - 733 participantes

438 diferentes empresas/instituições envolvidas

\section{Congressos}

- 4 edições do "Congresso Brasileiro de Polímeros"

- IV SLAP/II SIAP/VI IMC (internacional)

Totais: 3.036 participantes -1.469 trabalhos apresentados

\section{Publicações}

- 1 Catálogo de Serviços Técnicos de Laboratório

- 1200 testes laboratoriais

- 98 instituições e empresas participantes

- 20 edições do "Boletim Informativo"

- 28 edições da Revista "Polímeros: Ciência e Tecnologia"

- 129 artigos publicados

31 matérias

18 entrevistas

\section{Seminários e Reuniões Técnicas}

- 13 encontros/seminários* - 3 volumes - 29 palestras publicadas

* 6 em parceria com USP, AEA, UNESP, ABTB, ABC, ABM, UFSCar

- Reuniões das Comissões Técnicas:

- "Identificação e Caracterização:

50 reuniões/49 palestras

12 testes interlaboratoriais -2 workshops

- Reciclagem de polímeros:

16 reuniões/22 palestras -2 workshops .

- Reologia e Processamento:

7 reuniões/13 palestras -1 workshop

- Outras Comissões (até 1995): 12 reuniões 


\title{
Quadro de Associados
}

\section{Sócios Patrocinadores}

\author{
Basf S/A \\ Bayer Polímeros S/A \\ Ciba Especialidades Químicas Ltda. \\ GE Plastics South America S/A \\ Mercedes-Benz do Brasil S/A \\ Nitriflex S/A Ind. e Com. \\ OPP Petroquímica S/A \\ Polibrasil Resinas S/A
}

\section{Sócios Coletivos}

Alcoa Alumínio S/A

Branco Ind. e Com. Ltda.

Casa da Moeda do Brasil

Cia Vidraria Santa Marina/Vetrotex do Brasil

Clariant S/A

Cofade - Sociedade Fabricadora de Elastômeros

Cromex Brancolor Ltda.

Cytec do Brasil Ltda.

Dacarto S/A Indústria de Plásticos

Daicolor do Brasil Ind. e Com. Ltda.

Dart do Brasil Ind. e Com. Ltda.

Dinateste Ind. e Com. Ltda.

Elf Atochem Brasil Química Ltda.

Fastplas Indústria e Comércio Ltda.

FCC Química Ltda.

Fiat Automóveis S/A

FMC do Brasil Ind. e Com. Ltda.

Ford Brasil S/A

Formtap Ind. e Com. S.A

Imp. e Export. Medidores Polimate Ltda

Inapel Embalagens

Indústrias Romi S/A

Ipiranga Comercial Química S/A

Ipiranga Petroquímica $\mathrm{S} / \mathrm{A}$

Irmãos Semeraro Ltda.

Itap S/A - Divisão Cromex Resinas

Johnson \& Johnson Ind. e Com. Ltda.

\author{
Milliken Chemical \\ Mixcim Indústria e Comércio Ltda. \\ Multi União Com. e Usinagem Ltda. \\ Multibrás Eletrodomésticos S/A \\ Perkin-Elmer Ind. e Com. Ltda. \\ Petrobrás/Cenpes \\ Petronyl Ind. e Com. de Poliamidas Ltda. \\ Petroquímica Triunfo S/A \\ Piovan do Brasil Ind. e Com. Ltda. \\ Pirelli Pneus S/A \\ Polialden Petroquímica S/A \\ Policarbonatos do Brasil S/A \\ Produtos Elétricos Corona Ltda. \\ Raitek Ind. e Com. Plásticos de Engenharia Ltda. \\ Rank Pneus Ltda. \\ Rhodia Brasil S/A \\ Robert Bosch Ltda. \\ Sab Wabco do Brasil S/A \\ Shell Brasil S.A. Divisão Química \\ Telebrás - Telecomunicações Brasileiras S/A \\ Ticona Polymer Ltda. \\ Unipac Embalagens Ltda. \\ Uniroyal Química S/A \\ Waltap S/A Ind. e Com. de Plásticos \\ Wedco América do Sul Ltda.
}

\section{Instituições Sócias}

\author{
ABPE - Associação Brasileira de Tubos de Polietileno e Sistemas - SP \\ Associação Pró-Ensino em Santa Cruz do Sul - RS \\ Centro Acadêmico Horácio Lane - SP \\ Centro de Caracterização e Desenvolvimento de Materiais - CCDM - SP \\ Centro de Tecnologia Industrial-Senai - BA \\ Centro Tecnológico de Polímeros - Senai - RS \\ CFP Senai Nilo Betanin - RS \\ Escola Senai Mario Amato - SP \\ Escola Técnica Tupy - SC \\ Faculdade de Engenharia Química de Lorena - SP \\ Fundação Escola Tec. Liberato S.V. Cunha - RS \\ Fundação Universidade de Caxias do Sul - RS \\ Senai - Centro de Formação Profissional Alvimar Carneiro de Rezende - MG \\ Senai - Centro de Formação Profissional Cid. Ind. Curitiba - PR \\ UFBA - Instituto de Química - BA \\ UFSCar - Depto de Engenharia de Materiais - SP \\ Universidade Estadual de Ponta Grossa - PR
}


ver os profissionais da área mediante realização de congressos, seminários, reuniões, intercâmbio cultural, publicação de livros, periódicos, estudos e pesquisas, manutenção de biblioteca especializada e estímulo à fundação e desenvolvimento de escolas e laboratórios de polímeros.

Esses objetivos estavam ligados à necessidade de se criar uma Associação independente, politicamente apartidária e sem fins lucrativos, capaz de congraçar todas as pessoas físicas e jurídicas do setor. Este tem sido justamente um dos maiores méritos da $\mathrm{ABPol}$ e que lhe dão um caráter ímpar. A imparcialidade, o não-favorecimento deste ou daquele segmento, mas tão somente o setor de polímeros e seus profissionais como um todo, tornaram a Associação o ambiente ideal para a troca de experiências e a busca de soluções técnico-científicas. Além disso, possibilitou a interação da ABPol com os mais variados setores da indústria e do meio acadêmico do Brasil e do exterior e, mais recentemente, com instituições tradicionais como INP - Instituto Nacional do Plástico e Society of Plastics Engineers - SPE Seção Brasil.

Analisando a amplitude dos objetivos da ABPol, há de se reconhecer que 10 anos é um espaço de tempo relativamente pequeno para que todos já tivessem sido atingidos, mas não é exatamente isso o que constatamos, excetuada a manutenção de biblioteca especializada. Os números significativos nos resultados alcançados (vide quadros), ratificam os anseios, as necessidades e a união da comunidade de polímeros em torno de sua Associação, o que também é confirmado pela relação das empresas e instituições asso- ciadas, além de aproximadamente 800 sócios pessoa física, pertencentes a empresas e centros universitários e de P\&D.

\section{A visão dos presidentes}

Sonhar e fazer do sonho uma realização do nível da $\mathrm{ABPol}$ tem sido uma tarefa exaustiva, possível somente com muito empenho pessoal, abnegação e - sobretudo - visão de futuro. As diretorias da ABPol, sobretudo a provisória e a imediatamente seguinte, contaram com renhidos defensores e divulgadores da Associação junto à comunidade os quais tiveram, também, de vencer todos os vendavais das "recessões" que assolaram o país. A ABPol venceu às custas de muita luta e idealismo.

Para que se tenha uma idéia da unanimidade de ideais que sempre norteou a instituição, seguem, resumidas, algumas posições dos "ex" e do atual presidente da ABPol, que avaliaram: - o papel da ABPol perante o setor de polímeros no Brasil e os objetivos atingidos durante sua administração; - qual a missão da Associação para o futuro do setor dentro do contexto acadêmico e empresarial; - como aumentar a contribuição da ABPol para a comunidade.

\section{Sílvio Manrich (gestão 1988-1993)}

Como toda entidade sem fins lucrativos, livre e criativa, a ABPol, Associação de indivíduos e instituições, trabalha em prol do fortalecimento e crescimento das atividades culturais, científicas, tecnológicas e filosóficas do setor. Sabe-se que o caminho mais eficaz para isso é o alargamento de esferas públicas não-governamentais cuja maior virtualidade é garantir a sociabilidade política de pessoas e instituições. No Brasil, verificou-se a inexistência de uma Associação independente no setor de polímeros que congregasse de forma não-tendenciosa, empresas, universidades e institutos de pesquisa. A ABPol desde sua fundação primou pelo congraçamento dos indivíduos que atuam na área e, para atingir esses objetivos, tem promovido atividades culturais, congressos, cursos, encontros através de comissões e publicado atualidades tecno-científicas de interesse amplo.

Quando um ideal não cabe apenas em você, ele transborda, e se o ideal tem autenticidade, a inspiração de compartilhá-lo resulta na sintonia com aqueles que também anseiam pelos mesmos objetivos. Foi desse modo que assumi duas gestões como presidente da ABPol, além de ter contribuído durante o primeiro ano como presidente provisório. Nesses 5 anos a ABPol foi criada e cresceu graças aos sócios que a alavancaram. Nesse período, realizou-se o $1^{\circ} \mathrm{e}$ o $2^{\circ}$ CBPol (1991 e 1993), promoveu-se o lançamento da revista "Polímeros: Ciência e Tecnologia". Tanto os congressos como a revista são marcos do sucesso da associação e são ferramentas importantes para a ABPol exercer suas proposições iniciais. A interação e sintonia entre as diferentes instituições e pessoas foi a 
ferramenta básica para a construção do ideal.

Uma missão pode por si só delimitar uma entidade tão importante como a ABPol. A Associação deve ser uma realidade social inserida na comunidade setorial de polímeros e respondendo continuamente às necessidades que nascem e que sejam consonantes com suas finalidades básicas. É isso que dá legitimidade à Associação e possibilidade dela contribuir para as grandes propostas político-econômicas e sociais do país. Especificamente, a ABPol está se empenhando como Entidade Tecnológica Setorial - ETSPolímeros para contribuir com o fortalecimento tecnológico do setor, buscando alternativas e capacitando empresas para inovação tecnológica, resultando em maior competitividade, conforme objetivos detalhados na matéria da edição Jul/Set 97 , págs. 13 a 17, da revista "Polímeros: Ciência e Tecnologia".

A ETS-Polímeros está alicerçada no conceito "parcerias". As empresas hoje sabem que avanços tecnológicos dependem do contexto tanto mundial quanto regional. Dentro desse contexto estão as universidades e centros de P\&D e as agências governamentais de fomento que, em parceria com as empresas podem propiciar um sinergismo vantajoso. A ABPol, através da ETS-Polímeros gera, portanto, múltiplos benefícios. Tanto as empresas quanto o setor acadêmico e de pesquisa evoluem com parcerias fortes e bem direcionadas. A interação universidade-empresa tende a ser ampliada e a convergir para sinergismos que ainda hoje não estão plenamente explorados, mas que o serão por intermédio de parcerias sólidas, nascidas de interesses mútuos e tendo como pilastra entidades setoriais fortes.
A ABPol é a própria comunidade associada, englobando pessoas físicas e jurídicas. A ampliação do número de associados e a participação efetiva daqueles já sócios é a principal forma de ampliar a autocontribuição. Considero as Comissões Técnicas como o melhor fórum para gerar idéias e ações. É o caso das comissões de Identificação de Polímeros, a de Reciclagem e a de Reologia e Processamento, onde são trazidas e analisadas necessidades reais. A participação nessas e em outras comissões que serão criadas trará um inestimável crescimento da ABPol, porque os associados estarão crescendo. A ABPol deve, portanto, fazer um esforço para cativar mais indivíduos e instituições. Crescer, mudar, inovar fazem parte da vida e do sinergismo de uma associação.

Outra forma de aumentar a contribuição da ABPol são as parcerias, a exemplo da interação com SPE, INP, Plastivida, entre outros. Numa comunidade tão pequena como a do setor de polímeros, conjugar esforços irá agregar valores a todos e, Francisco José Xavier de Carvalho para a ABPol continuar a crescer, deve buscar sempre novos caminhos.

\section{Francisco José Xavier de Carvalho (gestão 1994/1995)}

"O papel da ABPol é, sem dúvida, o de fornecer ao setor de polímeros em todos os seus segmentos a formação e a orientação científica e tecnológica necessárias ao desenvolvimento do mesmo de uma forma adequada às condi- ções sócio-econômicas e tecnológicas brasileiras. As ferramentas para esta tarefa são as que a ABPol já maneja com competência: os cursos, seminários, workshops, congressos, publicações, etc. É muito importante que a direção da ABPol tenha a capacidade de analisar o setor e diagnosticar a prioridade, as necessidades e a forma de abordar cada um dos principais segmentos: ensino e pesquisa, matérias-primas, transformadores e usuários de polímeros.

Assumimos a presidência da ABPol no momento de importantes mudanças na economia do país, tornando imperiosa a adaptação ao novo sistema quando, em substituição à ciranda financeira na movimentação das empresas, vieram a produtividade e qualidade determinando a competitividade. As empresas, em busca da economia de escala que as tornava mais competitivas, procuravam crescer o mercado. Verificamos a necessidade de atuar na formação e esclarecimento dos potenciais usuários de polímeros que, por problemas na formação dos projetistas de quase todas as áreas de engenharia, careciam dos conhecimentos mínimos necessários para especificar com segurança produtos à base de polímeros.

Foram criadas em parceria com as empresas produtoras de resinas, alguns transformadores, associações técnicas e outros, Comissões Técnicas para a abordagem do setor cliente. Destas, destacaram-se a de Saneamento, que resolveu o impasse entre os fabricantes de PEAD e a área de saneamento; a Comissão de Construção Civil, que 
mostrou as dificuldades do setor em utilizar polímeros e permitiu vislumbrar um mercado interessante, mas não teve continuidade para alcançar resultados concretos. A Comissão de Caracterização, em sua subcomissão da indústria automobilística, realizou também importantes trabalhos nesta direção. Foi criada a Comissão Técnica de Polímeros e Fibras Naturais, motivada pela busca internacional de matérias-primas oriundas de fontes renováveis, considerada uma vocação natural do país. Esta comissão já realizou dois simpósios internacionais, sendo que o último em maio deste ano.

A missão da ABPol para o futuro é traçar os caminhos do desenvolvimento tecnológico do setor de polímeros, colaborando com a sua atualização de uma forma compatível com a realidade do país. O elevado nível da comunidade acadêmica e o seu efetivo intercâmbio com os grandes centros de ciência e tecnologia, constitui uma podero-

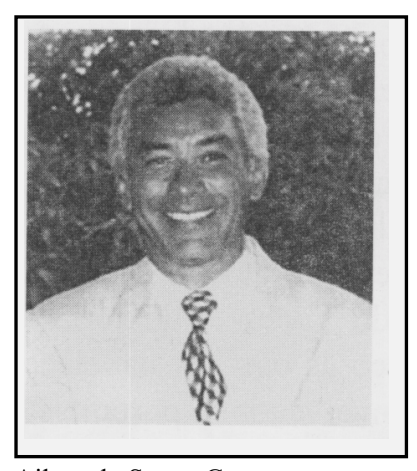

Ailton de Souza Gomes

\section{Ailton de Souza Gomes (gestão 1996/1997)}

"O grande papel da ABPol é o de servir de fonte de divulgação, de consulta, de treinamento de pessoal e promotora de eventos no setor sa ferramenta de prospecção tecnológica que a ABPol deve utilizar nesta missão de auxiliar na escolha dos caminhos do desenvolvimento. Nesta missão é importante que se tenha o conhecimento da realidade sócio-econômica e mercadológica do país, para que se possa adaptar ou selecionar adequadamente as novas tecnologias.

Uma forma de aumentar a contribuição da ABPol para a comunidade de polímeros no Brasil seria o estabelecimento de parceria com outras entidades, como ABIPLAST, INP, ABIMAQ, SENAI, universidades e outros, para a criação de um de polímeros no Brasil. Na administração anterior a ABPol procurou atender essas metas através do incentivo às Comissões de Caracterização, Reciclagem e de Reologia e Processamento; através da criação de Regionais no Sul, no Rio de Janei-

ro e na Bahia; na realização de seminários, cursos e o $4^{\circ}$ Congresso de Polímeros; na criação da ETSPolímeros.

A grande missão da ABPol para o futuro do setor de polímeros será a de fonte de referência para todos os tipos de ações no setor. No contexto acadêmico, através da divulgação de artigos técnico-ci-

entíficos na revista e Edson Roberto Simielli realização de cursos,

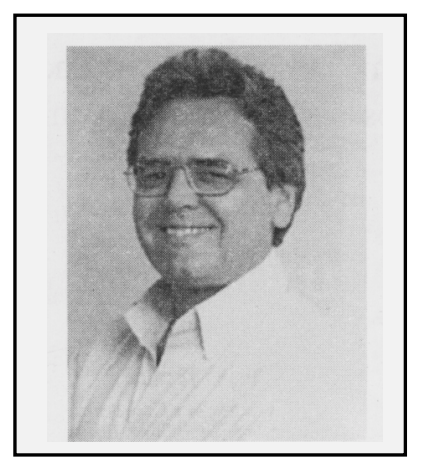

\section{Edson Roberto Simielli (gestão 1998/1999)}

Por conter no seu quadro de associados pessoas físicas, empresas públicas e privadas, universidades e entidades voltadas à pesquisa e desenvolvimento, a ABPol tem um papel fundamental na conciliação, interpretação e solução das necessidades destes setores que se dedicam à área de Polímeros. A ABPol é a entidade credenciada para promover o sinergismo entre os diferentes setores da comunidade de Polímeros e, para atingir este objetivo, estamos incentivando, na minha administração: - a parceria com outras entidades, como INP, SPE, PLASTIVIDA e Instituto do PVC; - o relacionamento com profissionais de outros países; o fortalecimento das regionais. Através das Comissões Técnicas procuramos abrir espaços seminários e congressos nacionais. para o setor de transformação, mo- 
tivando outros setores da Indústria de Polímeros a se associarem como, p. ex., de elastômeros enquanto melhoramos a comunicação com todos os associados através da Internet.

A grande missão da $\mathrm{ABPol}$ está na capacitação técnica dos profissionais que atuam na indústria de polímeros; na divulgação dos trabalhos técnico-científicos desenvolvidos pelas Universidades e Centros de Pesquisa e no treinamento sobre novas tecnologias desenvolvidas no setor. Para que esta missão seja atingida, cursos de treinamento e os Congressos realizados ou apoiados têm sido a ferramenta utilizada com sucesso.

Assim, acredito que quanto mais serviços prestarmos ao setor de Polímeros, quanto mais preciso formos na identificação e solução das necessidades dos diferentes setores, mais e mais associados, tanto pessoa física como jurídica teremos, conseqüentemente, mais sólido e forte seremos.

\section{Perspectivas}

A área de influência da Associação tem-se ampliado consideravelmente, graças à competência profissional de seus colaboradores e de seu Conselho Diretor, seja na organização dos mais variados encontros, nas publicações, na elaboração de projetos. São os membros da comunidade de polímeros elegen- do a ABPol como seu fórum de reunião, fato que levou à escolha da Associação como uma das entidades credenciadas pelo MCT para a instituição de uma Entidade Tecnológica Setorial de Polímeros, voltada para o setor produtivo e para o melhor aproveitamento das potencialidades dos centros geradores de conhecimento, através da estruturação de novos serviços tecnológicos e do aprimoramento dos já existentes.

Após o levantamento feito pela ABPol das carências e potencialidades que a área oferece e o encaminhamento dessas informações ao MCT, o Governo está equacionando sua forma de apoio às atividades propostas pela ETS - Polímeros e que devem ser desenvolvidas a curto, médio e longo prazo, envolvendo parcerias entre os diversos segmentos da sociedade. Paralelamente à ETS, e independente da concessão de recursos governamentais, a ABPol tem procurado agilizar a consecução das seguintes metas:

- Desenvolvimento do processo de apoio técnico às empresas do setor, envolvendo entidades e empresas para o direcionamento estratégico de custo e tecnologia em projetos multiclientes;

- Desenvolvimento do processo de organização e disponibilização de 3 módulos de Bancos de Dados abrangendo: a) informações referenciais do setor; b) competências técnicas e serviços de ensaios; c) oportunidades de negócio e ociosidade de máquinas;

- Desenvolvimento do processo e implantação do serviço de divulgação contínua das linhas de financiamento existentes que contemplam as necessidades do setor;

- Implantação de 3 novas Comissões Técnicas, com estímulo ao surgimento e gerenciamento de projetos cooperativos nas áreas de: a) Embalagens plásticas; b) Borrachas; c) Estudos de Mercado.

A curto e médio prazo a ABPol continuará: - promovendo os tradicionais cursos, seminários e reuniões técnicas; - editando a revista "Polímeros: Ciência e Tecnologia", já em seu $7^{\circ}$ ano consecutivo e com um número crescente de artigos técnico-científicos; - realizando o "Congresso Brasileiro de Polímeros" a cada dois anos; - incentivando a criação de núcleos regionais; estabelecendo parcerias com importantes instituições como INP, SPE, Plastivida e Instituto do PVC. A longo prazo, porém, os objetivos passam a ser mais ambiciosos, como, por exemplo, sediar o Congresso da IUPAC na próxima década e criar uma importante rede de interação e de serviços envolvendo a comunidade de polímeros como um todo. 